\title{
Modelling of QUENCH-03 and QUENCH-06 Experiments Using RELAP/SCDAPSIM and ASTEC Codes
}

\author{
Tadas Kaliatka, Algirdas Kaliatka, Virginijus Vileiniškis, and Eugenijus Ušpuras \\ Laboratory of Nuclear Installations Safety, Lithuanian Energy Institute, Breslaujos Street 3, LT-44403 Kaunas, Lithuania \\ Correspondence should be addressed to Tadas Kaliatka; tadas.kaliatka@lei.lt
}

Received 11 August 2014; Revised 7 November 2014; Accepted 16 November 2014; Published 2 December 2014

Academic Editor: Zhiwei Zhou

Copyright (C) 2014 Tadas Kaliatka et al. This is an open access article distributed under the Creative Commons Attribution License, which permits unrestricted use, distribution, and reproduction in any medium, provided the original work is properly cited.

To prevent total meltdown of the uncovered and overheated core, the reflooding with water is a necessary accident management measure. Because these actions lead to the generation of hydrogen, which can cause further problems, the related phenomena are investigated performing experiments and computer simulations. In this paper, for the experiments of loss of coolant accidents, performed in Forschungszentrum Karlsruhe, QUENCH-03 and QUENCH-06 are modelled using RELAP5/SCDAPSIM and ASTEC codes. The performed benchmark allowed analysing different modelling features. The recommendations for the model development are presented.

\section{Introduction}

The most important accident management measure to terminate a severe accident transient in a light water reactor is the injection of water to cool the uncovered degraded core. For instance, failure of the main and emergency cooling systems can lead to an accident with severe core degradation even with core meltdown. To prevent total meltdown of the uncovered and overheated core, the reflooding with water is a necessary accident management measure. Analysis of the Three Mile Island reactor 2 accident and the results of integral out-of-pile (CORA) and in-pile experiments (LOFT, PHEBUS, and PBF) have shown that before the water succeeds in cooling, the fuel rods there will be an enhanced oxidation of the Zircaloy cladding that in turn causes a sharp increase in temperature, hydrogen (exothermal zirconium-steamoxidation reaction) production, and fission product release [1-3]. The phenomena, related to the flooding of overheated core, were comprehensively investigated in QUENCH test program by FZK (Forschungszentrum Karlsruhe) Research centre (Karlsruhe Institute of Technology (KIT) since 2009). Within the frame of this program, the loss of coolant accidents in LWR (light water reactor) was analysed using an experimental reactor facility to determine the produced amount of hydrogen, the so-called hydrogen source term.
QUENCH experimental program started in the year 1996. Up to now in total 17 QUENCH tests were performed [4]. A review of objectives and boundary conditions is given in [5]. Two tests were performed with $\mathrm{B}_{4} \mathrm{C}$ control rods, one with an AgInCd control rod; all the others used an unheated but instrumented fuel rod simulator. The latest QUENCH tests deal with the behaviour of different cladding materials [6, 7], oxidation under air ingress conditions [8], and debris formation and its influence on quenching $[9,10]$. A new QUENCH-LOCA program is now underway. The overall objective of this bundle test series is the investigation of ballooning, burst, and secondary hydrogen uptake of the cladding under representative design basis accident conditions. Based on the posttest calculations of the QUENCH and QUENCH-LOCA, the capability of the best estimate codes (RELAP/SCDAPSIM, ASTEC, ATHLET CD, SOCRAT, etc.) can be established and evaluated (see, e.g., [9-13]).

Different researchers, performing modelling of different QUENCH experiments, are using different approaches. The goal of the present paper is to identify the general methods for modelling QUENCH experiments with the oxidation of Zircaloy cladding in the steam environment. These methods should cover different QUENCH experiments, different codes, and code versions. For this purpose the posttest 


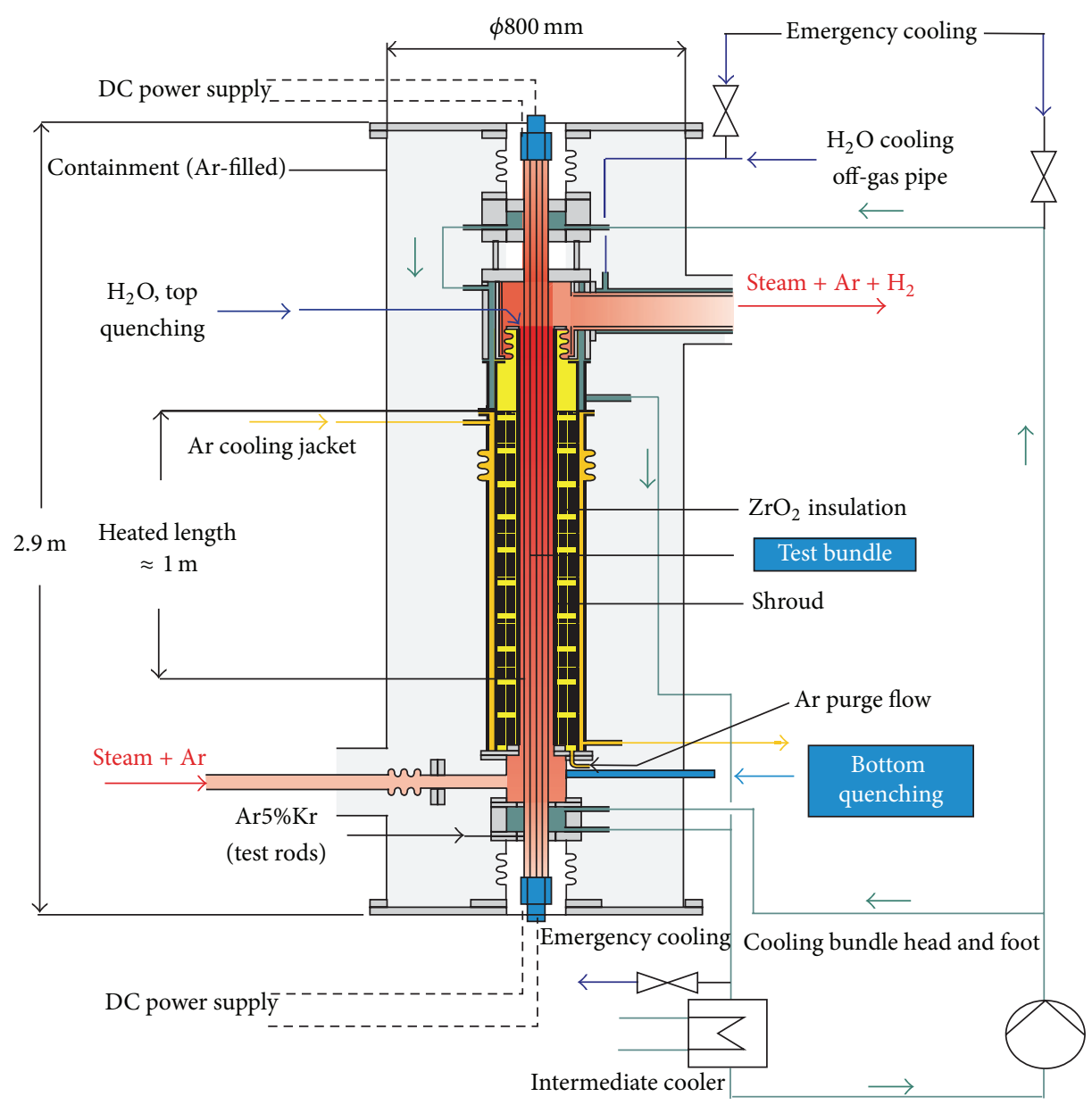

FIGURE 1: Test section of the QUENCH bundle [14].

calculations of the QUENCH-03 and QUENCH-06 tests with RELAP/SCDAPSIM and ASTEC are discussed below.

\section{Description of QUENCH-03 and QUENCH-06 Tests}

The main focus of the QUENCH tests lies on the analyses of the hydrogen generation especially during the reflood because in the CORA tests temperature escalations together with a high hydrogen production were detected, but the mechanisms, however, were not fully understood at that time [14]. The following chapter deals in general with the QUENCH facility at FZK and especially with the conduct of tests QUENCH-03 and QUENCH-06.

The QUENCH facility essentially consists of the out-ofpile bundle (see Figures 1 and 2). This bundle includes 20 heated rods, one unheated central rod that can be used for measurement devices or as a control rod, and four corner rods. The 21 simulator rods have a length of about $2.5 \mathrm{~m}$, while approximately $1 \mathrm{~m}$ of the heated rods is electrically heated.

The fuel rods in QUENCH facility are replaced by imitators, the tungsten heaters (outer diameter: $6 \mathrm{~mm}$ ), surrounded by annular pellets made of $\mathrm{ZrO}_{2}$ simulating the fuel pellets, which are bordered by Zircaloy- 4 claddings (the outer diameter: $\sim 11 \mathrm{~mm})$. The 21 rods and the 4 corner rods are arranged in a $5 \times 5$ matrix (see Figure 2). The bundle is surrounded by a shroud of three layers. The first one is made of Zircaloy at the inner side (outer diameter: $\sim 85 \mathrm{~mm}$ ), followed by a central $\mathrm{ZrO}_{2}$ insulation layer and a double-walled cooling jacket made of steel at the outer side, to provide the encasement of the bundle and to simulate the surrounding fuel rods in a real fuel element. The whole test section with the shroud is encapsulated by a steel containment (see Figure 1).

The QUENCH-03 experiment was performed at FZK on January 20, 1999. Feature of the QUENCH-03 experiment is that super-heated core is cooled with water; the water supply starts in the late phase (about $200 \mathrm{~s}$ after the fast transient beginning), when the fuel rod imitators temperature starts to increase sharply. During this experiment, the bundle of fuel rod imitators was heated up to $2100^{\circ} \mathrm{C}$. This very high temperature resulted in failure and partial melting of fuel rod imitator claddings and shroud.

The first phase of QUENCH-03 is the heat-up phase, where the experimental bundle was heated by a series of stepwise increases of electrical power from room temperature to approximately $900 \mathrm{~K}$ in an atmosphere of flowing argon $(3 \mathrm{~g} / \mathrm{s})$ and steam $(3 \mathrm{~g} / \mathrm{s})$. In order to stabilize the test setup 


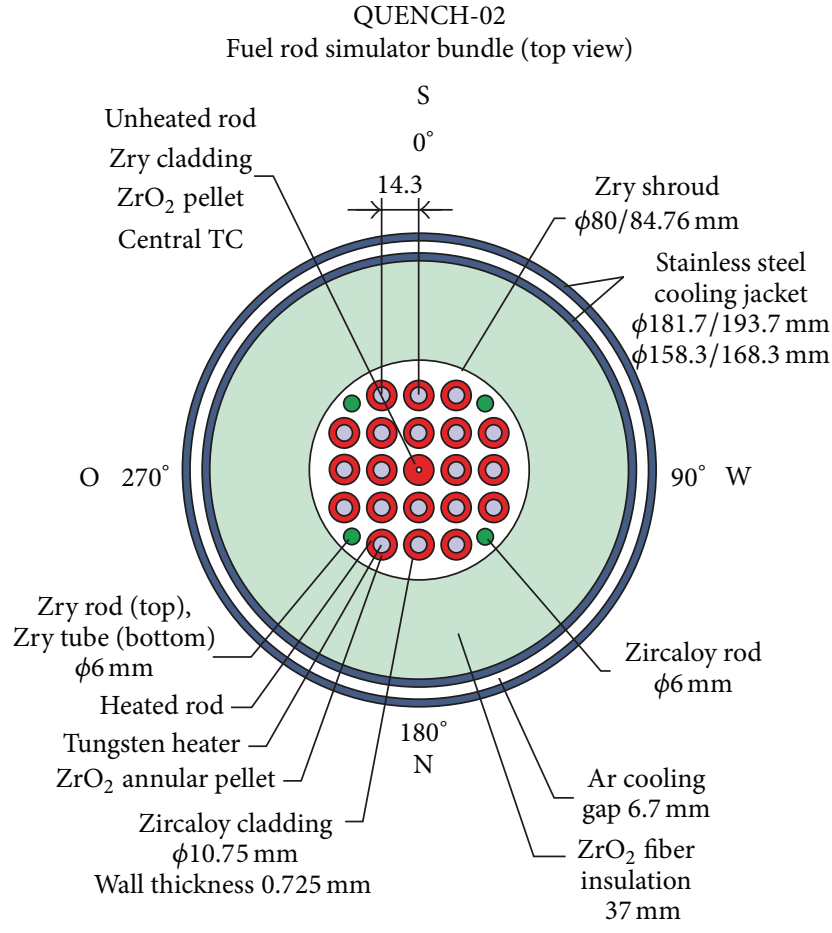

FIGURE 2: Test section and bundle cross-section of the QUENCH bundle [14].

the reached temperature was held for about $900 \mathrm{~s}$ with an electrical power input of $3.75 \mathrm{~kW}$. During this stabilization phase, shortly before the end, the data logging was switched on [14]. In the QUENCH-03 test, the preoxidation phase can be neglected because at the beginning of the transient phase, the claddings should only be lightly oxidized with an oxide layer of approximately $30 \mu \mathrm{m}$, as it is in the normal operation state of a pressurized water reactor (PWR).

The transient phase followed and started at about $900 \mathrm{~s}$ and lasted roughly up to time point $2600 \mathrm{~s}$. The bundle was ramped from $3.75 \mathrm{~kW}$ at $0.42 \mathrm{~W} / \mathrm{s}$ per rod to $18.4 \mathrm{~kW}$ giving an average temperature increase of about $0.4 \mathrm{~K} / \mathrm{s}$ between $900 \mathrm{~K}$ and $1400 \mathrm{~K}$ and about $1.6 \mathrm{~K} / \mathrm{s}$ between $1400 \mathrm{~K}$ and $2070 \mathrm{~K}$. At the end of the transient phase, the electrical power reached a value of about $18.4 \mathrm{~kW}$ and $30.1 \mathrm{MJ}$ of electrical energy in total was put into the system. Afterwards the thermocouples in the upper area of the shroud and upper bundle elevations show the same behaviour, due to the exothermal zirconium-steam-reaction that runs faster at higher temperature levels. According to the calculation presented in [15], this reaction gave an additional energy input of $18.4 \mathrm{MJ}$ into the system, from which $16.3 \mathrm{MJ}$ was released during quenching. The thermocouples at $750 \mathrm{~mm}$ bundle elevation detected a maximum temperature over $2400 \mathrm{~K}$ causing a thermocouple failure at that elevation and higher [14]. The progression of the QUENCH-03 test is presented in Figure 3.

Reaching the defined temperature of $2400 \mathrm{~K}$ inside the bundle at $2600 \mathrm{~s}$ followed by the initiation of the final quench phase, in which the reflood water was injected firstly at a high

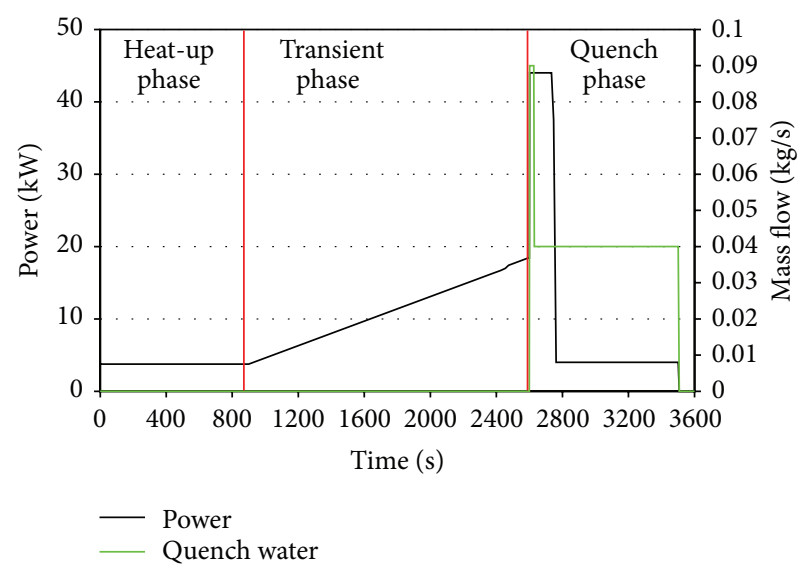

FIgURE 3: Progression of the QUENCH-03 test [14].

rate of $90 \mathrm{~g} / \mathrm{s}$ for $25 \mathrm{~s}$ to fill the lower plenum. With the initiation of reflooding the electrical power was increased from $18.4 \mathrm{~kW}$ to $44 \mathrm{~kW}$ to compensate the convective heat losses occurring due to the boiling of the injected water at the hot structure material. At $2625 \mathrm{~s}$ the water injection rate was reduced to $40 \mathrm{~g} / \mathrm{s}$. The water mass flow resulted in a local flooding rate at the bottom of $1.3 \mathrm{~cm} / \mathrm{s}$. After reaching the maximum at $2627 \mathrm{~s}$ the electric power was reduced to $37.5 \mathrm{~kW}$ until $2747 \mathrm{~s}$. During this period substantial temperature escalations occurred in the upper bundle area so that the claddings and the shroud failed at about $2627 \mathrm{~s}$. Due to this failure, it came to melt formation and relocation, which resulted in an increase of the surface available for oxidation and subsequently resulted in an additional massive hydrogen production. In the period from 2747 to $2762 \mathrm{~s}$, the electrical power was reduced from 37.5 to $4 \mathrm{~kW}$ to simulate the typical decay heat of a LWR [14].

The QUENCH-06 experiment was performed at FZK on December 13, 2000 [16]. It consisted of one preparatory and four operational phases. The operational phases represent calculation domain of this analysis. In the preparatory phase, the bundle was heated to one level and filled with argon and steam in order to make a system check. The first operational phase is a heat-up phase, when the bundle was brought to an intermediate temperature level $(\sim 1400 \mathrm{~K})$. The second is a preoxidation phase, when the temperature was kept constant up to the time at which the maximum oxide layer reached the experiment designed value. The third is a transient phase, when the temperature increased up to the experiment designed value for the onset of quenching phase. The last of the operational phases is a quench phase, when the steam supply was stopped and water was added, simulating the reflood.

Before the heat-up phase, during the preparatory regime, as in the previous QUENCH experiments, the bundle was heated by a series of stepwise increases of electrical power from room temperature to nearly $900 \mathrm{~K}$ in an atmosphere of flowing argon $(3 \mathrm{~g} / \mathrm{s})$ and steam $(3 \mathrm{~g} / \mathrm{s})$. The bundle was stabilised at that temperature for about two hours, the electrical power being about $4 \mathrm{~kW}$. 
At the end of the stabilisation period the heat-up phase starts. The bundle was ramped by stepwise increases in power up to about $10.5 \mathrm{~kW}$ to reach an appropriate temperature for preoxidation $(\sim 1400 \mathrm{~K})$. During the preoxidation phase that temperature was maintained for about 1 hour by control of the electrical power to reach the desired oxide layer thickness $(\sim 220 \mu \mathrm{m})$. At the end of the preoxidation phase (which lasted from $1960 \mathrm{~s}$ to $6010 \mathrm{~s}$ ) the bundle was ramped at $0.32 \mathrm{~W} / \mathrm{s}$ per rod to start the transient phase. During heat-up, preoxidation, and transient phase the bundle was cooled with flowing steam and argon both having an inlet mass flow rate of approximately $3 \mathrm{~g} / \mathrm{s}$ and an inlet temperature that varied between $607 \mathrm{~K}$ and $650 \mathrm{~K}[16]$.

In QUENCH-06 (differently as in QUENCH-03) the quenching was initiated after long time preoxidation phase and after transient phase when two rod thermocouples showed temperature higher than $2000 \mathrm{~K}$. Quench phase began at $7179 \mathrm{~s}$ by shutting down the steam supply and with initiation of quench water injection. Within 5 seconds $4 \mathrm{~kg}$ of water was injected to fill the lower parts of the facility (fast water injection system). At the same time, the quench pump started to inject water from the bottom of the test section at a rate of approximately $42 \mathrm{~g} / \mathrm{s}$. The water used for quenching was at room temperature. About 25 seconds later, the electrical power was reduced from $18 \mathrm{~kW}$ to $4 \mathrm{~kW}$ within $17 \mathrm{~s}$ to simulate decay heat level. Quenching of the test section was completed within 260 seconds. Quench water injection and electrical power were then shut off, terminating the experiment. During the quench phase, argon injection was switched to the upper plenum to continue providing carrier gas for quantitative hydrogen detection [16]. The electrical power history is shown in Figure 4 indicating also the phases of the experiment.

\section{RELAP/SCDAPSIM Model of QUENCH Test}

RELAP/SCDAPSIM computer code is designed to describe the overall reactor coolant system thermal hydraulic response and core behaviour under normal operating conditions or under design basis or severe accident conditions [17]. The QUENCH experimental facility was modelled using RELAP/SCDAPSIM code versions mod 3.2, mod 4.0, and mod 3.5 [17]. QUENCH nodalization scheme is presented in Figure 5. The space between heated rods and the outer cooling loop of the QUENCH facility was modelled using RELAP5 components: pipe, timedependent volumes and junctions, single junctions, and others.

Imitators of fuel rods and surrounding shroud are modelled using the components of the SCDAP package: "fuel," "Cora," and "shroud." In total 5 components are described using SCDAP package:

(i) component 1: one central rod (not heated), modelled as a "fuel" element that is composed of $\mathrm{ZrO}_{2}$ pellets in the centre, a gas-filled gap, and cladding of Zircaloy;

(ii) component 2: 8 heated rods (around the central rod) which simulates heated fuel rods, modelled using "Cora" component which is composed of tungsten

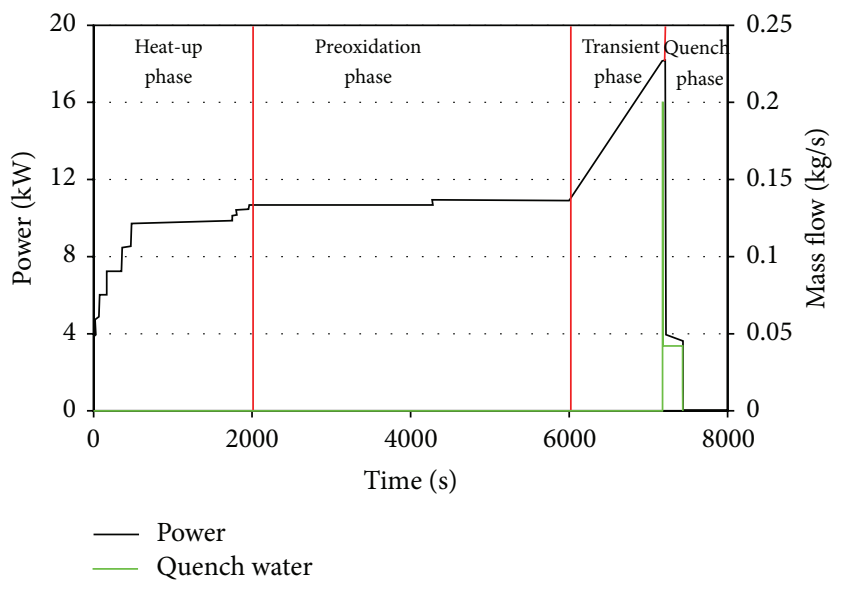

FIGURE 4: Total electrical power input of QUENCH-06 experiment [16].

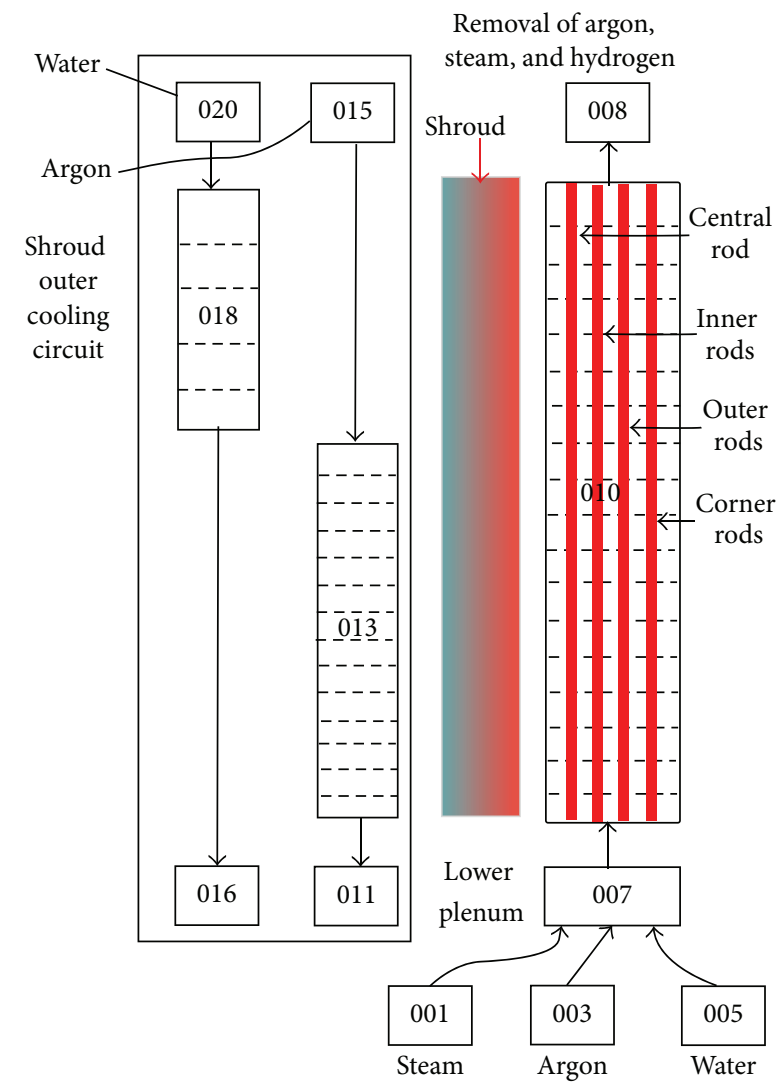

FIGURE 5: Nodalization scheme of QUENCH test, developed using RELAP/SCDAPSIM computer code.

heating elements in the centre, $\mathrm{ZrO}_{2}$ pellets, gas-filled gap, and cladding of Zircaloy;

(iii) component 3: 12 heated rods, modelled using "Cora" component;

(iv) component 4: the four rods in the corners, modelled as "fuel" component; 
(v) component 5: shroud of the bundle, modelled as "shroud" component, which consists of the inner Zircaloy layer, an insulating layer of $\mathrm{ZrO}_{2}$ and Inconel layer (using properties of stainless steel).

The first four components are connected to the RELAP5 structure, which describes space between heated rods, pipe element "010" (see Figure 5). Element "010" is divided in axial direction into 18 nodes with $0.1 \mathrm{~m}$ length. The heating area of fuel rod imitators is placed in the 4th to 13th nodes (total length of heated area is $1.0 \mathrm{~m}$ ). The fifth component (shroud of the bundle), in order to have heat exchange in the wall, is connected to hydrodynamic structures of RELAP5. This structure, pipe elements " 013 " and "018," is modelling the outer cooling circuit of the shroud. Total thickness of heat structure, which models the shroud component, is $1.2 \cdot 10^{-2} \mathrm{~m}$ and has 4 radial mesh layers. Element " 013 " in axial direction is divided into 13 nodes, and element " 018 " is divided into 5 nodes with $0.1 \mathrm{~m}$ length each.

\section{Modelling of QUENCH-03 and QUENCH-06 Tests Using RELAP5 Code}

In the QUENCH test facility, the fuel rods are replaced by electrically heated fuel rod imitators. Electrical power (measured during the experiments) was converted into the heat using the tungsten heaters. As it was already mentioned, for the modelling of electrically heated fuel rod imitators in the QUENCH test facility, the special component "Cora" was used in the SCDAP part. The special mathematical model was developed in the RELAP/SCDAPSIM computer code for the simulation of the electrical heat generation [17]. The total power input is specified by user input, while the axial and temperature-dependent thermal power release is calculated by the model. The electrical heat generation model computes the axial and temperature-dependent heat release in the heated area of the tungsten heater rod and also includes the effects of contact resistance (effect of the molybdenum electrode and the copper at the top and bottom of the tungsten heater). The model first computes the electrical resistance of copper, molybdenum, and tungsten. The model currently has the dimensions of the tungsten rod and molybdenum and copper electrodes built into the resistance equations. The specific dimensions are based upon the "Cora" heater rod elements. The resistances are calculated by the equations $[17,18]$

$$
\begin{aligned}
R_{\mathrm{Mo}}= & 2.25 \cdot 10^{-2}+5.36 \cdot 10^{-5} T_{\mathrm{Mo}} \\
& +1.38 \cdot 10^{-7} T_{\mathrm{Mo}}^{2}-2.22 \cdot 10^{-11} T_{\mathrm{Mo}}^{3}, \\
R_{\mathrm{Cu}}= & -7.89 \cdot 10^{-3}+9.9 \cdot 10^{-5} T_{\mathrm{Cu}} \\
& -5.49 \cdot 10^{-8} T_{\mathrm{Cu}}^{2}+3.13 \cdot 10^{-11} T_{\mathrm{Cu}}^{3}, \\
R_{w}(I)= & {\left[-0.0261+2.63 \cdot 10^{-4} \mathrm{~T}(I)+2.2 \cdot 10^{-8} T(I)\right] } \\
& \times D_{Z}(I) \cdot 3.5368 \cdot 10^{-2}, \quad I=1,2, \ldots, \mathrm{NAZ},
\end{aligned}
$$

where NAZ is the number of axial levels, $D_{Z}(I)$ is height of $I$ th axial node $(\mathrm{m}), T(I)$ is fuel rod center temperature at node $I(\mathrm{~K}), T_{\mathrm{Mo}}=0.5(T(\mathrm{NAZ})+350)(\mathrm{K})$, and $\mathrm{TC}_{u}=0.5\left(T_{\mathrm{Mo}}+\right.$ 350) (K).

The total resistance is then given by

$$
R_{t}=\sum_{I=1}^{\mathrm{NAZ}} R_{W}(I)+0.0086 \cdot\left(R_{\mathrm{Mo}}+R_{\mathrm{Cu}}\right)+0.0005 \text {. }
$$

The thermal power (heat generation) per unit length in each axial node is then

$$
\operatorname{UNUC}(I)=\frac{R_{w}(I)}{R_{t}} \cdot \frac{P_{t}}{D_{Z}(I)},
$$

where $P_{t}$ is the total input rod power.

In the RELAP/SCDAPSIM computer code this mathematical model could be realised in two different ways (depending on the code versions).

(1) First approach was used for the oldest RELAP/ SCDAPSIM code versions (mod 3.2 and older). In these code versions, for the description of heat generation in the fuel rods imitators, the power of "Cora" component is prescribed by the table in the input. In this case, the given power will be assumed in computer code as heat generated in the heater. In addition, using this first approach, in the "Cora" component the radius of tungsten heater rod should be indicated. For the QUENCH test facility it is assumed to be equal to $0.003 \mathrm{~m}$. However, in the experimental facility the part of heat is released in the molybdenum thimbles, which are connected to the both ends of tungsten heater. Using this first approach, the heat losses in the molybdenum wires and sliding contacts at both ends of the rods are not evaluated. So, in order to evaluate the losses of power and to get the best agreement with experimentally measured temperatures, the power of "Cora" component was reduced and heat loses from the shroud were increased.

(2) In the RELAP/SCDAPSIM mod 4.0 and RELAP/ SCDAPSIM mod 3.5 versions the second approach was used. In the "Cora" component the generated heat is calculated, describing electrical power, parameters of tungsten heater, and additional electric resistance (contact resistance of sliding contacts). It was assumed in the modelling that the radius of tungsten heater rod was $0.003 \mathrm{~m}$. The values of contact resistance, recommended for RELAP/SCDAP calculations in the articles $[16,19-21]$, vary from 2.8 to $4.4 \mathrm{~m} \Omega$. In our calculation, we assumed the value of this contact resistance to be equal to $3 \mathrm{~m} \Omega$. Using the second approach, the heat generation in fuel rods imitators is modelled describing electrical power supplied to the tungsten heater (which is measured during the experiment) and evaluating electrical resistance of contacts.

The future calculations will show that the assumptions and selection between the first and second modelling 


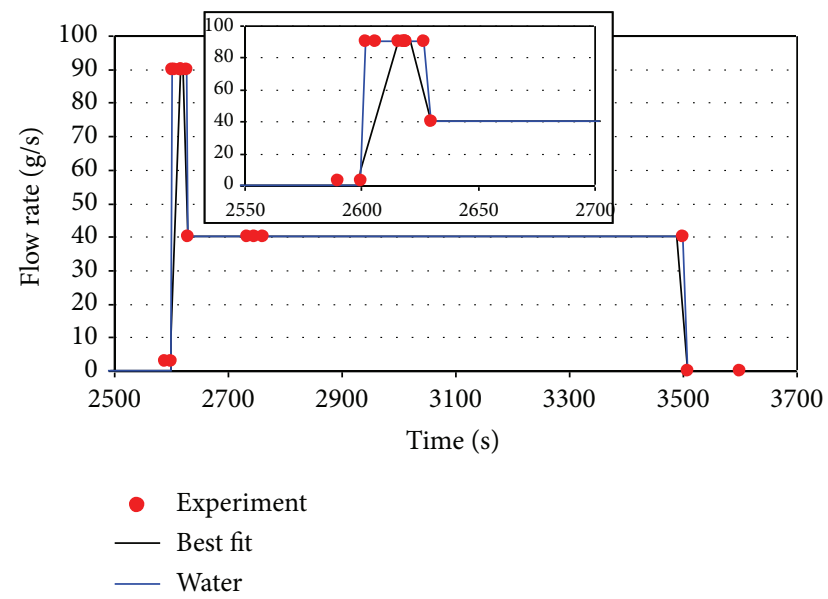

FIGURE 6: Flow rate of quenching water in different calculation sets.

approaches in "Cora" component have significant influence on the calculation results.

For the modelling of QUENCH-03 experiment, using the first approach of heat generation description, three sets of parameters were applied, describing the initial and boundary conditions:

(1) the flow rate of supplied water, heating power, generated in the fuel rods imitators, and thermal properties of porous $\mathrm{ZrO}_{2}$ shroud layer were assumed according to measurements (ATM), recorded during the QUENCH-03 experiment [14];

(2) the set of parameters selected in a way to reach the best coincidence with the experiment measurements (best fit);

(3) the third case is similar to the 2 nd case, but the flow rate of quenching water was assumed according to the experimental measurements [14] in the QUENCH-03 (water).

In the "best fit," the calculation results are in the best agreement with the experiment measurements, and in "water" cases the power generation in fuel rods imitators was reduced by $\sim 25 \%$ from the experimental values. The flow rate of quenching water was assumed to be a little different (see Figure 6) comparing to the experimental data in the "best fit" cases. The variations of $\mathrm{ZrO}_{2}$ shroud layer thermal properties for the three sets of parameters are presented in Figure 7. As it is presented in Figure 7(a), the shroud thermal conductivity of $\mathrm{ZrO}_{2}$ is increased by $80 \%$ in the cases of "best fit" and "water." In the same cases, the specific heat of $\mathrm{ZrO}_{2}$ is increased by $40 \%$ (see Figure 7(b)). The changes of these thermal properties (increasing thermal conductivity and specific heat) give larger heat losses through the shroud.

The QUENCH-03 test calculation results, using first approach of heat generation description in component "Cora" with RELAP/SCDAPSIM mod 3.2, are presented in Figures 8 and 9. The calculations were performed for three cases: (1) "ATM," (2) "best fit," and (3) "water." The values of experimental results were taken from the FZK report [14].

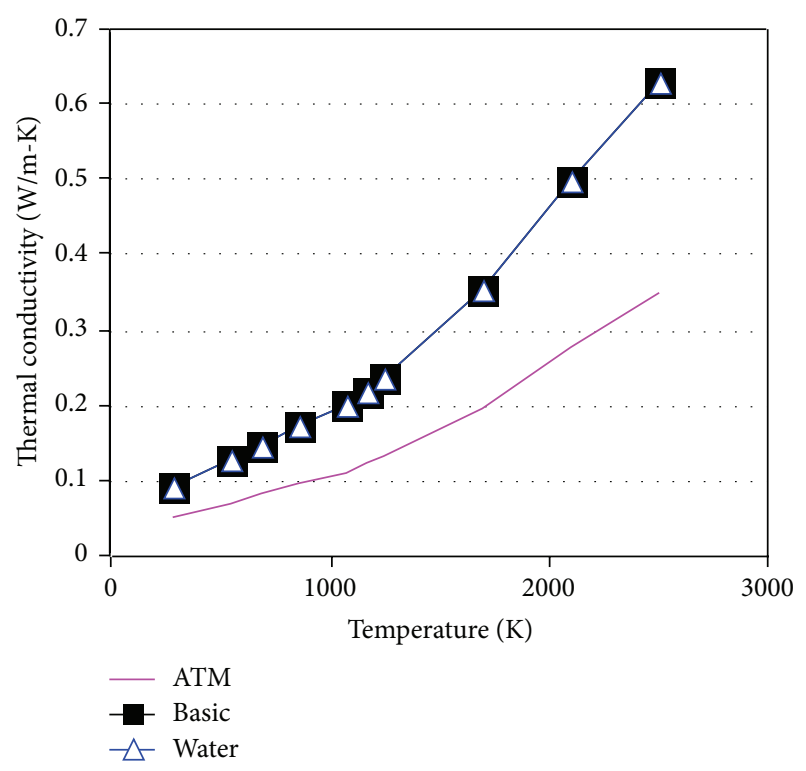

(a)

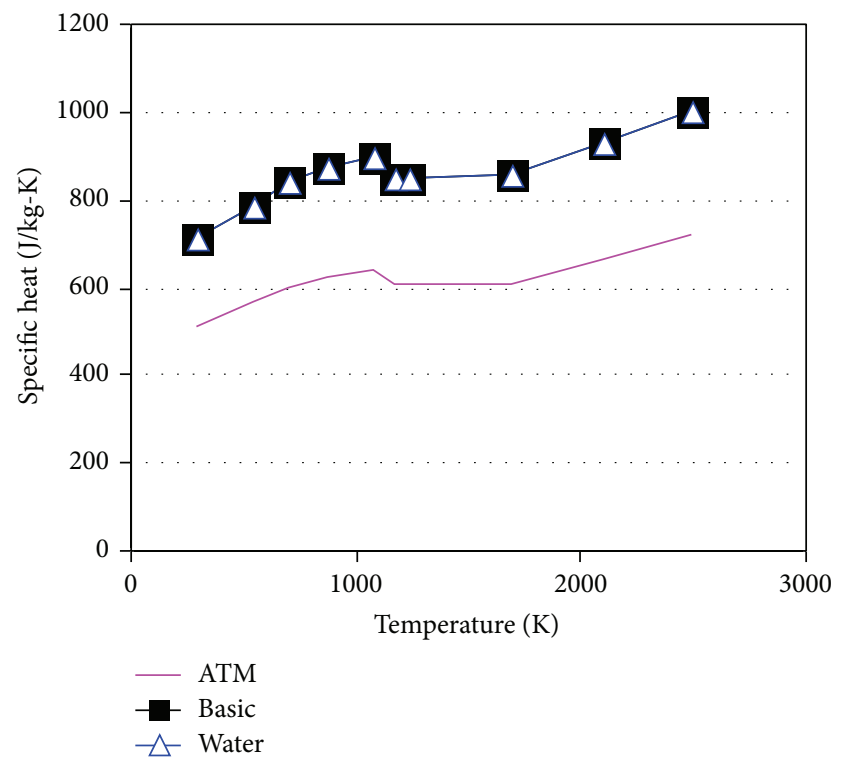

(b)

Figure 7: The thermal properties of $\mathrm{ZrO}_{2}$ shroud layer: (a) thermal conductivity, (b) specific heat.

The comparison of experimental data with the calculation results (see Figure 8) showed that since the boundary conditions are assumed according to experimental measurements (set of boundary conditions marked as "ATM"), the RELAP/SCDAPSIM mod 3.2 calculations give overestimated temperature values in fuel rod imitator cladding. Thus, if the first approach of heat generation description in component "Cora" is used (for the old RELAP/SCDAPSIM code versions), the power level decrease by $\sim 25 \%$ (comparing to the experimental data) of heat generation in imitators of fuel rods should be assumed. This is indicated by the agreement of measured and calculated temperatures at the constant 


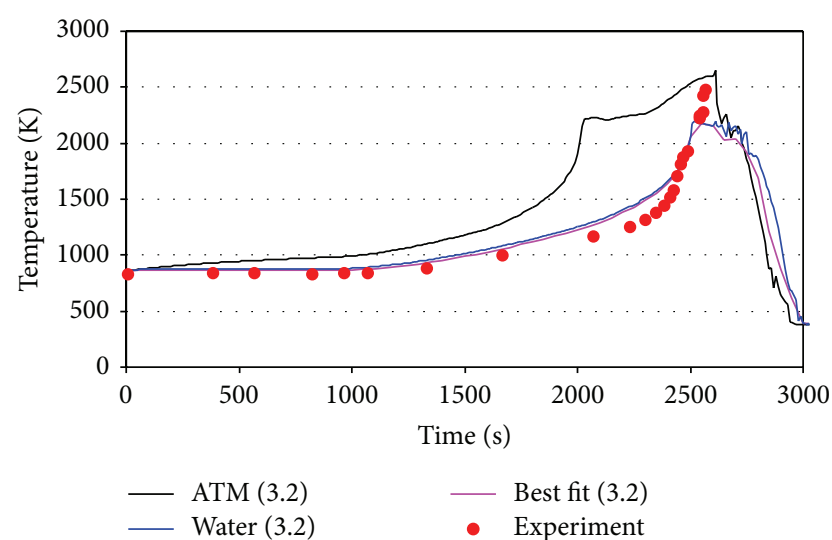

FIGURE 8: QUENCH-03 test calculation using RELAP/SCDAPSIM mod 3.2. The first approach of heat generation in "Cora" description. Fuel rod imitator cladding outer surface temperature in outer ring of bundle at $750 \mathrm{~mm}$ height.

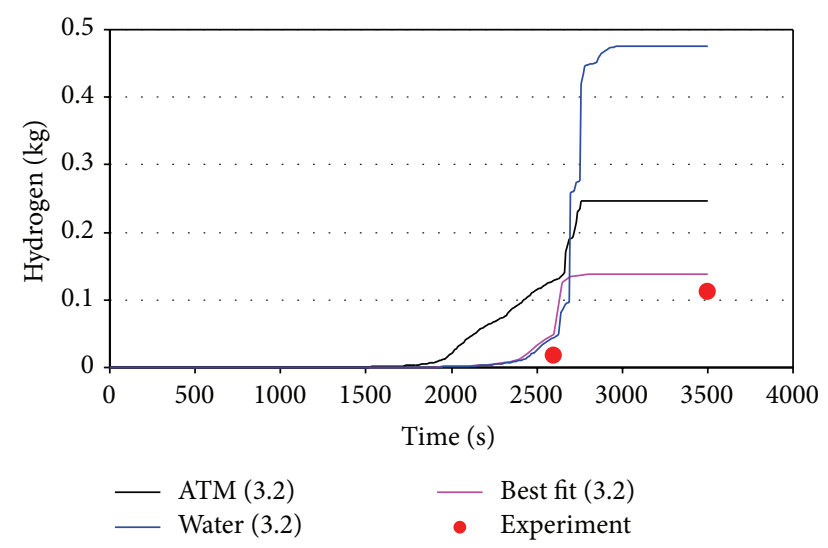

FIGURE 9: QUENCH-03 test calculation using RELAP/SCDAPSIM mod 3.2. The first approach of heat generation in "Cora" description. Total hydrogen mass of QUENCH-03 experiment.

power ("heat-up" phase). The slight change of water flow rate has insignificant influence on calculated temperatures in the upper part of the experimental bundle. However, the comparison of experimental data with the calculation results showed that comparatively small increase of amount of injected water leads to significant increase of amount of generated hydrogen (see Figure 9). This is because in calculation with the increased amount of water, the steamzirconium reaction takes place in a larger length of the bundle. This means that before the quenching phase, the energy accumulated in the bundle of fuel rods imitators is so high that during the first seconds of this phase the supplied water is not capable of removing the heat. All the water is converted into the steam, which reacts with the zirconium. Only after the sharp decrease of power, generated in the fuel rods imitators, the steam-zirconium reaction stops and the temperature of fuel rod imitator claddings starts to decrease. In more detail the first approach of description of the heat generation in "Cora" component is discussed in article [22].

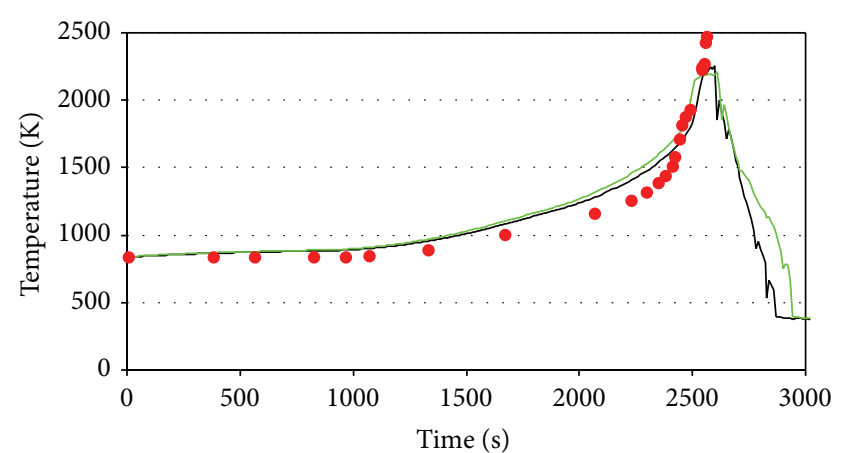

- Experiment

- SA "weak" oxidation $(\bmod 4.0)$

_ SA "enhanced" oxidation $(\bmod 3.5)$

FIGURE 10: QUENCH-03 test calculation using RELAP/SCDAPSIM mod 4.0 and mod 3.5. The second approach of heat generation in "Cora" description. Fuel rod imitator cladding outer surface temperature in outer ring of bundle at $750 \mathrm{~mm}$ height.

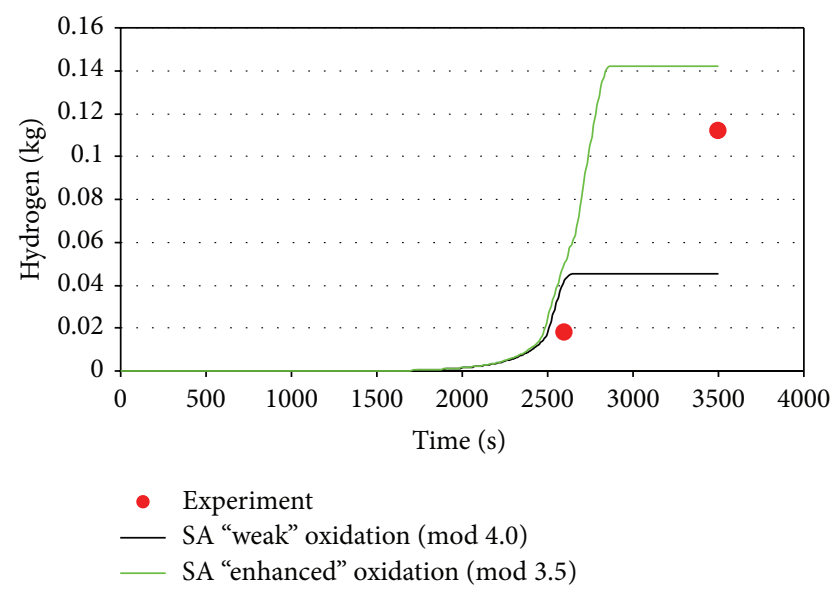

FIgURE 11: QUENCH-03 test calculation using RELAP/SCDAPSIM mod 4.0 and mod 3.5. The second approach of heat generation in "Cora" description. Total hydrogen mass of QUENCH-03 experiment.

The first approach of heat generation description in component "Cora" is rough and already outdated. Using the second approach of heat generation description in the bundle, the electrical power, radius of tungsten heater, contact resistance of sliding contacts, and radius of molybdenum thimbles (electrodes) are presented in fuel rod imitators, described as the "Cora" components. The QUENCH-03 test calculation results, using such approach, are presented in Figures 10-12. In the calculations, the simulator electrode dimensions in the "Cora" component were the same as in "ATM" set (the first approach). The water supply was chosen according to the measurements during the experiment.

For the calculations the two RELAP/SCDAPSIM versions were used: $\bmod 4.0$ and $\bmod 3.5$. The calculation results, performed using RELAP/SCDAPSIM mod 4.0 version, are marked as "SA ( $\bmod 4.0)$ " while the results, received using mod 3.5 version, are marked as "SA ( $\bmod 3.5)$." It is necessary 


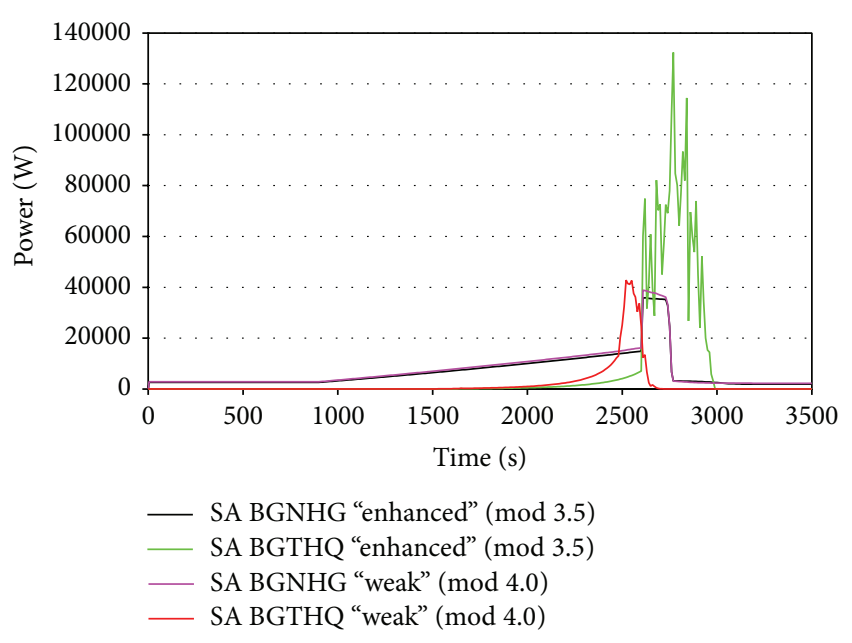

FIGURE 12: QUENCH-03 test calculation using RELAP/SCDAPSIM mod 4.0 and $\bmod 3.5$. The second approach of heat generation in "Cora" description. Total amount of core nuclear heat generation (BGNHG) and core total oxidation heat generation (BGTHQ).

to note that the RELAP/SCDAPSIM mod 3.5 is not yet a "frozen" version and is under the development within the international SCDAP Development and Training Program. The RELAP/SCDAPSIM mod 3.5 has few advantages, which were developed specially for the posttest analysis of QUENCH and others, reflooding and quenching phenomena related experiments (possibilities to choose different models for oxidation of Zircaloy cladding in the steam and air environments, possibilities to control the modelling of the slumping of liquefied cladding and its subsequent oxidation, and others). Using the RELAP/SCDAPSIM code mod 3.5 version, there are possibilities to model the steam-zirconium oxidation with enabled shattering and with disabled shattering oxidation models. The general material oxidation model, used in RELAP/SCDAPSIM code mod 3.5 version, calculates the generation of heat, production of hydrogen, and reduction of steam. This model uses oxidation rate equations with material temperatures defined by the component heat conduction model. Material oxidation is assumed to behave according to the parabolic rate equation

$$
\frac{d \delta}{d t}=\frac{A}{\delta} e^{(-B / T)}
$$

where $\delta$ is weight gain or layer thickness $\left(\mathrm{kg} / \mathrm{m}^{2}\right.$ or $\left.\mathrm{m}\right) ; T$ is temperature (K); $t$ is time (s); and $A$ and $B$ are parabolic rate constants taken form MATPRO [23].

This general model, for the calculation of behaviour of oxygen weight gain, is used for "weak" steam-zirconium oxidation case and the shattering oxidation model is disabled.

Chojnacki and Baccou [23] performing the modelling of reflood oxidation using SCDAP/RELAP5 proposed using the model of "enhanced" oxidation when the outer oxide layer of a fuel rod component is considered to shatter. This will occur when the following criteria are met:

(i) $\beta$ phase thickness less than or equal to $0.1 \mathrm{~mm}$; (ii) cooling rate greater than zero for four consecutive time steps within the temperature range of 1.150 to $1.560 \mathrm{~K}$.

In the RELAP/SCDAPSIM code mod 3.5 version, in addition to the shattering criteria, a special RELAP5 logical trip was introduced, which when true, will assume the shattering process of the oxide layer on all components at all axial nodes. It should be noted that this in the RELAP/SCDAPSIM input specified option will lead to the maximum oxidation rate and to the drastically conservative results, since all in-core oxide is shattered and should dramatically overpredict the rate of hydrogen production [23]. In the case of implementation of the "enhanced" oxidation model (the model with enabled shattering), the oxidation model was modified to track two oxide histories: a physical oxide history and an effective oxide history. The physical oxide history was unchanged and is used for all the mass balance and heat conduction modelling. An effective oxide history was represented as two independent variables: the effective oxide thickness and the effective oxygen weight gain. These variables are tracked for each axial node of each component and represent $\delta$ in (4). When the reflood criteria are met, the effective oxide thickness is reset to model fresh unoxidized Zircaloy, and the oxygen weight gain is reset to the difference between the physical oxygen weight gain and the oxygen in the removed oxide layer.

RELAP/SCDAPSIM mod 4.0 version did not have an option to choose the shattering model to model zirconium oxidation in the steam environment; thus only "weak" steamzirconium oxidation case could be simulated using this code version.

As it is presented in figures, both versions of RELAP/ SCDAPSIM code demonstrated good agreement of calculated and measured temperatures within the first 2500 seconds of experiment (see Figure 10). However, in the quench phase, when the overheated fuel rods are cooled by water, the RELAP/SCDAPSIM mod 3.5 version with the "enhanced" oxidation model shows difference with experimental measurements and calculation results, received using mod 4.0. The total amount of generated hydrogen, calculated using RELAP/SCDAPSIM mod 4.0 version, is significantly below the measured during the experiment value, while the calculated using mod 3.5 version value is by $15 \%$ above the measured value (see Figure 11). This is because of early mentioned approaches for the steam-zirconium oxidation modelling in different computer code versions:

(i) "weak" zirconium oxidation (disabled shattering oxidation) model in RELAP/SCDAPSIM mod 4.0 version;

(ii) "enhanced" zirconium oxidation (enabled shattering oxidation) model in RELAP/SCDAPSIM mod 3.5 version.

The total amount of core nuclear heat generation (BGNHG) and core total oxidation heat generation (BGTHQ) for the calculations using both RELAP/SCDAPSIM code versions are presented in Figure 12. As it is presented in the figure, the total amount of core heat generation (BGNHG) is 
the same for both versions and corresponds to the power of electrical heaters in the fuel rod imitators. The steamzirconium reaction and hydrogen generation start when the peak temperature of components made from zirconium exceeds the $1100 \mathrm{~K}$. Before this time moment (approximately $t=2000 \mathrm{~s}$ ) the value of core total oxidation heat generation (BGTHQ) is equal to zero. Later, due to increase of temperature, the exothermic steam-zirconium reactions intensify and heat generation due to oxidation increases. According to the RELAP/SCDAPSIM code mod 4.0 calculations, the core total oxidation heat generation (BGTHQ) reaches the peak value $(42000 \mathrm{~W})$ at the time moment $t=2550 \mathrm{~s}$ and later starts to decrease. In this code version, the increased flow rate of supplied water (at the beginning of quenching phase, $t=$ 2600 s) does not evoke the intensification of steam-zirconium reaction; it is assumed in the simulation that the shattering of zirconium oxide layer does not occur. The heat generation due to oxidation (BGTHQ) ends at $t=2680 \mathrm{~s}$, when the fuel rod imitator cladding temperature decreases below $1100 \mathrm{~K}$. In the RELAP/SCDAPSIM code mod 3.5 calculations, the increase of flow rate of supplied water at the beginning of quenching phase leads to the secondary oxidation; the Boolean variable introduced into the RELAP/SCDAPSIM mod 3.5 code version [23] is triggered and the shattering of the oxide layer on all components at all axial nodes starts. Due to this process, the huge amount of additional heat due to oxidation (BGTHQ) is generated (see Figure 12). This also explains the high mass of hydrogen in the mod 3.5 calculation (see Figure 11).

The factor, which complicates the modelling of QUENCH-03, is the formation of massive debris zones and molten pools in this test. As revealed in various analyses of this test (including reports of KIT experimentalists $[4,14])$, it cannot be adequately treated without additional considerations of enhanced oxidation of corium melt.

Correspondingly, an enhanced release of hydrogen during quench phase was detected in this test owing to oxidation of molten pools. The heat, generated during the zirconium oxidation reaction in the RELAP/SCDAPSIM mod 3.5 calculation, was transferred to the bottom part of the model of experimental bundle. As a result, the calculated temperature of fuel rod imitator cladding and the total amount of generated hydrogen mass using RELAP/SCDAPSIM mod 3.5 version with the default SCDAPSIM model for the zirconium oxidation in a steam environment are in sufficient agreement with the measurement results (see Figures 10 and 11). This demonstrated that the RELAP/SCDAPSIM code mod 3.5 version (with enabled shattering oxidation, "enhanced" oxidation model) allows evaluating the oxidation of corium melt. To receive a better agreement with the measurements in the experiment, the additional "tuning" of input deck, using special options for the modelling of the slumping of liquefied cladding and its subsequent oxidation and others is necessary.

The experience, received during modelling of QUENCH03 test, was used in performance of QUENCH-06 model, using RELAP/SCDAPSIM mod 4.0 and mod 3.5 versions. The values of experimental results were taken from the FZK report [16]. The modelling was performed only using second approach, where the heat generation in the component
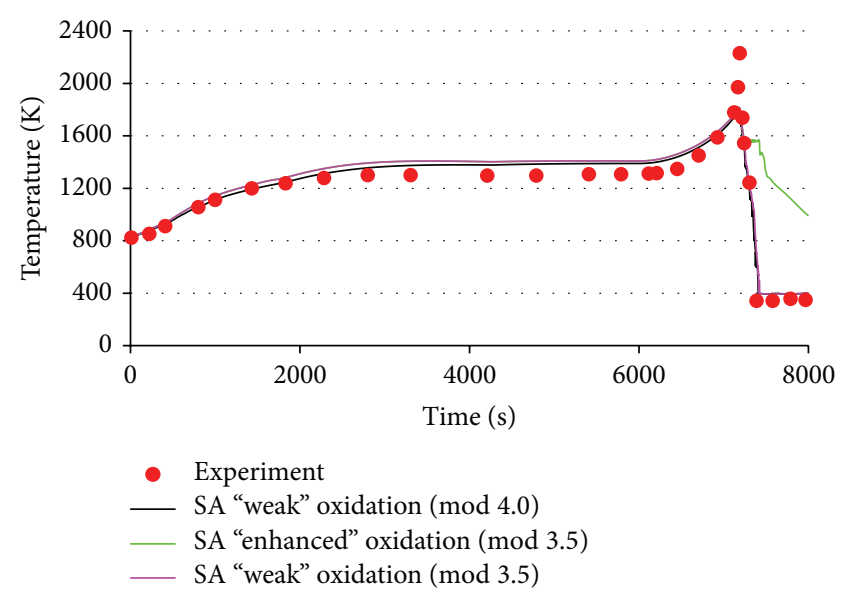

FIGURE 13: QUENCH-06 test calculation using RELAP/SCDAPSIM $\bmod 4.0$ and mod 3.5. Fuel rod imitator cladding outer surface temperature in inner ring of bundle at $750 \mathrm{~mm}$ height.

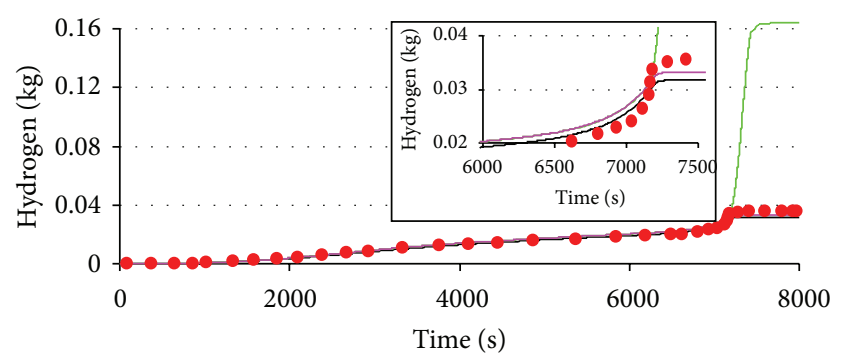

- Experiment

- SA "weak" oxidation $(\bmod 4.0)$

_ SA "enhanced" oxidation $(\bmod 3.5)$

— SA "weak" oxidation $(\bmod 3.5)$

FIGURE 14: QUENCH-06 test calculation using RELAP/SCDAPSIM $\bmod 4.0$ and $\bmod$ 3.5. Total hydrogen generation.

"Cora" was described by the electrical power and contact resistance. The quenching water was supplied according to experiment measurements. The QUENCH-06 test calculation results are presented in Figures 13-15. As in the QUENCH-03 case, during the first phases of experiment (heat-up, preoxidation, and transient), both versions of RELAP/SCDAPSIM code demonstrate a good agreement. The results are also in the good agreement with experimental measurements. In the quench phase, the RELAP/SCDAPSIM mod 4.0 version demonstrated a sufficient agreement of calculated temperatures; unfortunately, the calculated temperatures of fuel rod imitator cladding are lower (the peak value of cladding temperature is $1800 \mathrm{~K}$ in calculations, comparing to maximal measured during the experiment temperature of $2200 \mathrm{~K})$. As it is shown in Figure 14, the total amount of generated hydrogen at time interval $t>7500 \mathrm{~s}$, calculated using mod 4.0 , is approximately by $11 \%$ lower as measured. Using the RELAP/SCDAPSIM mod 3.5 version two calculations were performed: (1) with the enabled shattering oxidation ("enhanced" zirconium oxidation in a steam environment) model and (2) with disabled shattering oxidation ("weak" 


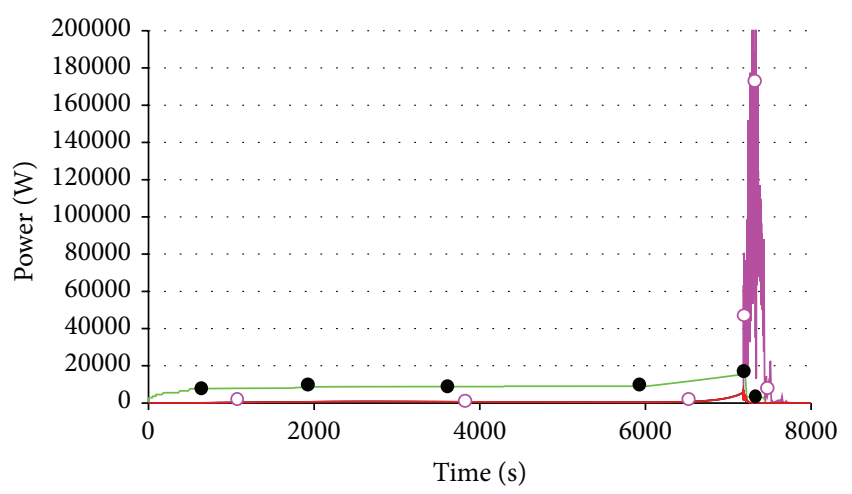

_ SA BGNHG "enhanced" oxidation $(\bmod 3.5)$

- - SA BGTHQ "enhanced” oxidation $(\bmod 3.5)$

- $\mathrm{SA}$ BGNHG "weak” oxidation $(\bmod 4.0)$

— SA BGTHQ “weak" oxidation $(\bmod 4.0)$

FIGURE 15: QUENCH-06 test calculation using RELAP/SCDAPSIM mod 4.0 and mod 3.5 with default SCDAPSIM model for the zirconium oxidation. BGNHG: total core heat generation. BGTHQ: core total oxidation heat generation.

zirconium oxidation) model. In Figures 13-15 the calculation results, performed using RELAP/SCDAPSIM mod 4.0 version, are marked as "SA (mod 4.0)," the results, received using mod 3.5 version with enabled shattering oxidation model, as "SA (mod 3.5) 'enhanced oxidation," and the results, received using mod 3.5 version and disabled shattering oxidation model, as "SA 'weak oxidation' $(\bmod 3.5)$."

The differences between the QUENCH-03 and QUENCH-06 experiments are not only the presence of preoxidation phase in QUENCH-06. The power of heat generation in experimental bundle and the flow rate of water during quench phase are significantly lower in QUENCH-06 experiment (see Figures 3 and 4). Thus, the level of cladding temperature of fuel rod imitators is lower in this experiment. The formation of massive debris zones and molten pools does not appear, and the evaluation of enhanced oxidation of corium melt is not necessary. This explains why the RELAP/SCDAPSIM code mod 4.0 version gives a satisfactory agreement of calculation results with the measurements. The calculation results, received using the disabled shattering oxidation ("weak" zirconium oxidation) model in RELAP/SCDAPSIM mod 3.5 version and RELAP/SCDAPSIM code mod 4.0 version, are very similar. Contrarily, using the mod 3.5 version with enabled shattering oxidation ("enhanced" oxidation) model, we received a very big amount of generated hydrogen, few times higher than measured values (see Figure 14). As it is presented in Figure 13, the calculation using enabled shattering oxidation model gives slow fuel rods imitator temperature decrease during the quenching phase $(t>7200 \mathrm{~s})$. This is because in such case, due to assumption of too much of intensive steam-zirconium reaction, a too big amount of oxidation heat generation (BGTHQ) was calculated (see Figure 15). As it is presented in this figure, the huge amount of heat due to zirconium exothermal oxidation reactions is generated after the start of supply of quench water in the calculation using RELAP/SCDAPSIM mod 3.5 with enabled shattering oxidation model. In the QUENCH-06 experiment, because of slow power increase in experimental bundle and presence of preoxidation phase, the fast oxidation of zirconium does not occur, unlike in QUENCH-03 experiment.

Thus, the RELAP/SCDAPSIM mod 3.5 version with enabled shattering oxidation ("enhanced" oxidation) model is suitable for the fast and very intensive steam-zirconium reaction modelling (as in the QUENCH-03 experiment). For the slow oxidation cases the RELAP/SCDAPSIM mod 3.5 version with disabled shattering oxidation ("weak" zirconium oxidation) model should be used. Such conclusion is confirmed by the paper [24], which demonstrated a very good agreement of QUENCH-06 experiment measurements with the calculations results using RELAP/SCDAPSIM mod 3.5 version.

\section{Modelling of QUENCH-06 Test Using ASTEC Code}

ASTEC (Accident Source Term Evaluation Code) [25] was jointly developed for several years by the French Institut de Radioprotection et de Sûreté Nucléaire (IRSN) and the German Gesellschaft für Anlagen und Reaktorsicherheit $\mathrm{mbH}$ (GRS) to simulate all the phenomena that occur during a severe accident in a water-cooled nuclear reactor.

The initial and boundary conditions for the ASTEC model use are the same as in RELAP/SCDAPSIM model. The simple nodalization scheme of ASTEC model for the modelling of QUENCH experimental facility has been developed and is presented in Figure 16.

QUENCH-06 experiment fuel bundle model includes models of nonheated central rod ROD1, two rings of electrically heated rods (the inner ring with 8 rods, ROD2; the outer with 12 rods, ROD3) and corner rods. Shroud is modelled as manufactured with all layers. Flow rate through the core is modelled by employing two fluid channels VAP1 for steam and argon and LIQ1 for water. Grids are also modelled. In the axial direction QUENCH facility core was divided into 32 nodes. The circuit resistance value of $0.2 \mathrm{~m} \Omega$ and the $\mathrm{Zr}$ oxidation modelling Urbanic correlation were used as recommended in [26].

The QUENCH-06 test calculation results using ICARE module are presented in Figures 17, 18, and 19. With ICARE module calculated temperatures are in good agreement with experimental data in heat-up, preoxidation, and transient phases. In the quench phase, as in RELAP/SCDAPSIM calculations (see Figure 13), the calculated temperatures in the upper part of fuel rod imitator cladding are lower, comparing to the values, measured during the experiment.

The comparison of measured and calculated generation of hydrogen is presented in Figure 19. The different correlations, describing zirconium oxidation in water steam, were activated in ASTEC calculation. The activations of Prater or best fit correlations in ICARE module lead to the significantly higher rate of generated hydrogen in the quench phase. If the Sokolov correlation is used, the calculated hydrogen generation rate is lower in preoxidation and transient phases, while 


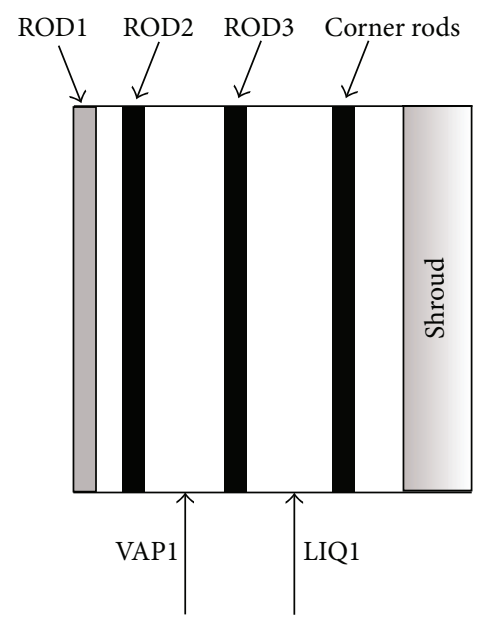

FIGURE 16: Nodalization scheme of QUENCH test, developed using ASTEC code ICARE module.

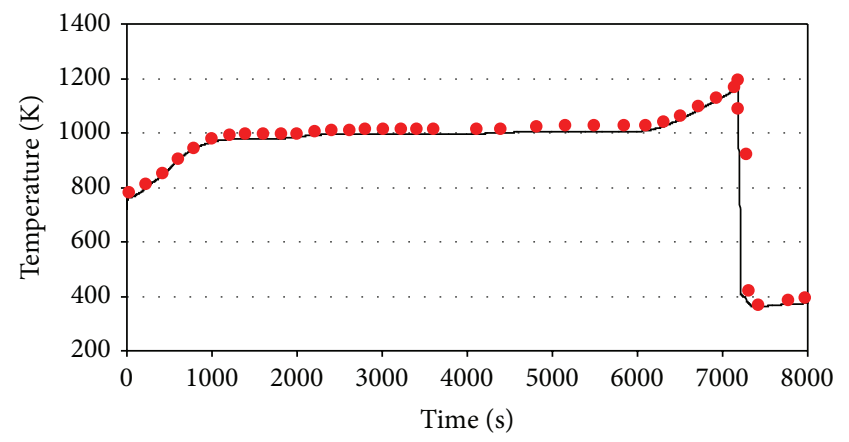

- Experiment

- ICARE

FIgURE 17: QUENCH-06 test calculation using ASTEC code. Fuel rod imitator cladding temperature in outer ring of bundle at $350 \mathrm{~mm}$ height.

in the quench phase, the calculated hydrogen generation rate exceeds the measured values (see Figure 19). This is probably due to a nonadequate model of oxide layer growth during initial phases and shattering during quench phase. As it is presented in Figure 19, the best agreement of calculated hydrogen generation rate with experimental measurements is reached with the recommended Urbanic correlation in the report [26]. Only for quench phase calculated hydrogen amount is underestimated about $15 \%$.

\section{Concluding Discussion}

The analysis and simulation of the QUENCH experiments allows reaching two goals. First, it provided a better understanding of the processes in reactor core during the severe accident-the overheating of core and further injection of water (quenching). Second, it revealed the limitations in computer codes, when calculating the zirconium oxidation, oxide layer formation, and shattering. The QUENCH experimental facility models were developed and the QUENCH-03

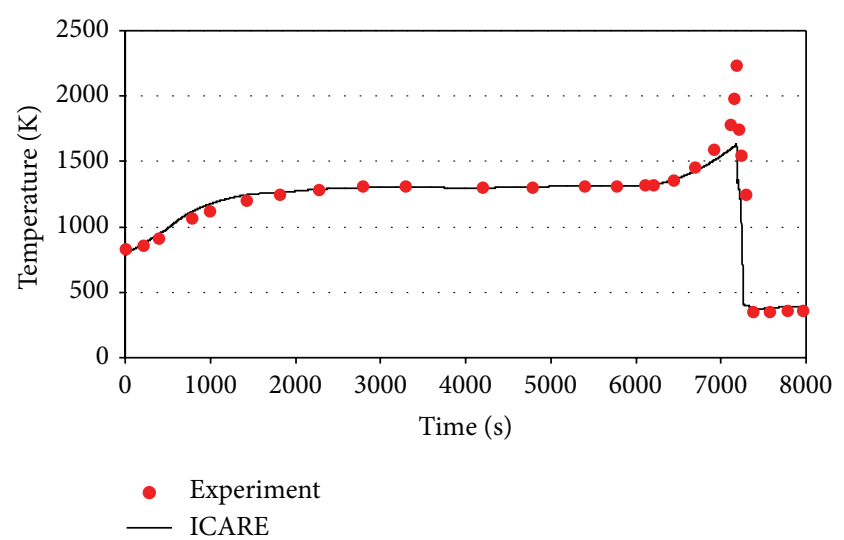

FIGURE 18: QUENCH-06 test calculation using ASTEC code. Fuel rod imitator cladding temperature in outer ring of bundle at $750 \mathrm{~mm}$ height.

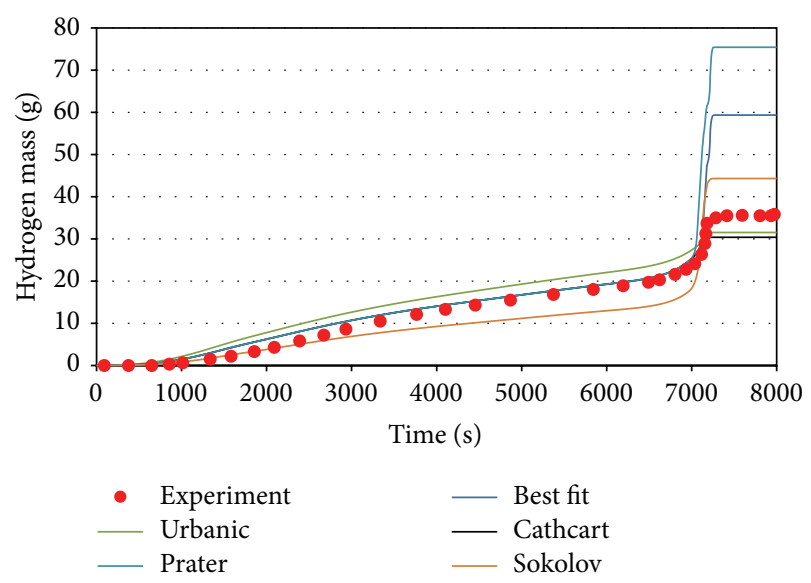

FIGURE 19: QUENCH-06 test calculation using ASTEC code. Total hydrogen generation.

and QUENCH-06 tests benchmarks were performed using RELAP5/SCDAPSIM and ASTEC computer codes. The main goal of present paper was to identify the general methods for modelling QUENCH experiments with the oxidation of Zircaloy cladding in the steam environment for different codes and code versions.

In the QUENCH experiments the heat in fuel rods was generated by electrical heaters. There are two possibilities to model the heat generation in fuel rod imitators in RELAP5/SCDAPSIM code: (1) by describing the heat release and (2) by describing the electrical power and modelling of simulators electrode (radius of tungsten and contact resistance). Using the first approach, in the RELAP5/SCDAPSIM mod 3.2 benchmark, it was shown that to receive good agreement between calculated and measured fuel rod temperatures, it is necessary to decrease the heat generation in the bundle of fuel rod imitators (comparing to the experimentally measured electrical power). This decrease of heat generation allows evaluating the additional resistance outside the bundle. The best agreement of calculated and measured fuel rods and shroud temperatures is reached when 
the power, relieved from the fuel bundles, is reduced by $\sim 25 \%$. The comparatively small increase of amount of injected water in the RELAP5/SCDAPSIM mod 3.2 benchmark leads to significant increase of amount of generated hydrogen.

On the other hand, this first approach of heat generation description in component "Cora" is rough and already outdated. The use of such approach can be justified only if the newest versions of RELAP5/SCDAPSIM code are not available and mod 3.2 version is employed. When the second approach for heat generation in "Cora" components was used (employing RELAP5/SCDAPSIM mod 4.0 and mod 3.5 versions), the best agreement was received with the contact resistance equal to $3 \mathrm{~m} \Omega$. Both versions of RELAP/SCDAPSIM code demonstrate a good agreement of calculated and measured temperatures of fuel rod imitator cladding during the heat-up and transient phases and a satisfactory agreement during the quench phase. The RELAP/SCDAPSIM mod 3.5 version with enabled shattering oxidation model allows evaluating the oxidation of corium melt, which takes place in QUENCH-03 test. Thus, this RELAP/SCDAPSIM code version gives a better agreement of calculated amount of generated hydrogen with the experiment measurements, comparing to mod 4.0 version with a disabled shattering oxidation model. To receive the better agreement with the measurements in the experiment, the special options for the modelling of steam-zirconium oxidation and oxidation of corium melt for this particular case should be used.

The modelling features using RELAP5/SCDAPSIM code, determined for the QUENCH-03 test, are suitable to the QUENCH-06 test. This confirmed the correctness of the chosen general ideas for modelling of the QUENCH experiments. The newer versions of RELAP5/SCDAPSIM code ( $\bmod 4.0$ and $\bmod 3.5)$ were used for the modelling of QUENCH-06 test. Only the approach with description of electrical power and modelling of contact resistance of electrodes (fuel rod imitators) was used for the modelling of QUENCH-06 test. The RELAP5/SCDAPSIM code mod 4.0 version gives a satisfactory agreement of calculation results with the measurements. The RELAP/SCDAPSIM mod 3.5 version with a disabled shattering oxidation model also gives very similar results. Such option should be used for the slow oxidation cases. The RELAP/SCDAPSIM mod 3.5 version with enabled shattering oxidation model is suitable only for the fast and very intensive steam-zirconium reaction modelling (as in the QUENCH-03 experiment).

The QUENCH-06 tests benchmark using ASTEC code shows that the Urbanic correlation for cladding oxidation gives the best agreement between the calculated and measured hydrogen generation rates. Assuming the identical initial and boundary conditions in ASTEC and RELAP5/ SCDAPSIM models, the very similar behaviour of fuel rods temperatures and amount of generated hydrogen were received comparing to the calculations employing RELAP5/ SCDAPSIM mod 4.0 version.

The further study of the influence of shroud thermal conductivity and the investigation of the behaviour of shroud temperatures and new possibilities of RELAP5/SCDAPSIM mod 3.5 code are required to solve all modelling issues.

\section{Conflict of Interests}

The authors declare that there is no conflict of interests regarding the publication of this paper.

\section{Acknowledgments}

The authors of the paper would like to express their gratitude to C. M. Allison from Innovative Systems Software (ISS) and SCDAP Development \& Training Program for the possibility to test newest RELAP5/SCDAPSIM code versions and help with the code assimilation.

\section{References}

[1] J. M. Broughton, K. Pui, D. A. Petti, and E. L. Tolman, "A scenario of the three mile island unit 2 accident," Nuclear Technology, vol. 87, no. 1, pp. 34-53, 1989.

[2] P. Hofmann, S. J. L. Hagen, V. Noack, G. Schanz, and L. K. Sepold, "Chemical-physical behavior of light water reactor core components tested under severe reactor accident conditions in the CORA facility," Nuclear Technology, vol. 118, no. 3, pp. 200$224,1997$.

[3] P. R. Hobbins and G. D. Mcpherson, "Summary of results from the LOFT LP-FP-2 test and their relationship to other studies at the power burst facility and of the Three Mile Island Unit 2 accident," OECD/LOFT final Event, 1991.

[4] Karlsruhe Institute of Technology, "QUENCH Programme at KIT-QUENCH test matrix," November 2014, http://quench .forschung.kit.edu/.

[5] M. Steinbrück, M. Große, L. Sepold, and J. Stuckert, "Synopsis and outcome of the QUENCH experimental program," Nuclear Engineering and Design, vol. 240, no. 7, pp. 1714-1727, 2010.

[6] J. Stuckert, J. Birchley, M. Grosse, B. Jaeckel, and M. Steinbrück, "Experimental and calculation results of the integral reflood test QUENCH-14 with M5 cladding tubes," Annals of Nuclear Energy, vol. 37, no. 8, pp. 1036-1047, 2010.

[7] J. Stuckert, J. Birchley, M. Große, B. Jaeckel, and M. Steinbrück, "Experimental and calculation results of the integral reflood test QUENCH-15 with ZIRLO cladding tubes in comparison with results of previous QUENCH tests," Nuclear Engineering and Design, vol. 241, no. 8, pp. 3224-3233, 2011.

[8] J. Stuckert and M. Steinbrück, "Experimental results of the QUENCH-16 bundle test on air ingress," Progress in Nuclear Energy, vol. 71, pp. 134-141, 2014.

[9] J. Stuckert, J. Birchley, M. Grosse et al., “The QUENCH-DEBRIS test experimental results and modeling," in Proceedings of the 6th SARNET International Meeting (ERMSAR '13), Avignon, France, October 2013.

[10] A. D. Vasiliev and J. Stuckert, "Post-test calculation of the QUENCH-17 bundle experiment with debris formation and bottom water reflood using thermal hydraulic and severe fuel damage code SOCRAT/V3," in Proceedings of the International Conference on "Nuclear Energy for New Europe 2013" (NENE '13), NENE-2013-407, Bled, Slovenia, September 2013.

[11] L. Fernandez-Moguel and J. Birchley, "Planning support and preliminary post-test analysis of QUENCH-LO using SCDAP/RELAP and SCDAPSIM," in Proceedings of the International Congress on Advances in Nuclear Power Plants (ICAPP '11), Paper 11030, Nice, France, May 2011. 
[12] T. Hollands, "Simulation of QUENCH-L0 with ATHLET-CD," in Proceedings of the 17th QUENCH Workshop, Karlsruhe, Germany, November 2011.

[13] A. D. Vasiliev and J. Stuckert, "Application of thermal hydraulic and severe accident code SOCRAT/V3 to bottom water reflood experiment QUENCH-LOCA-0," Nuclear Engineering and Design, vol. 261, pp. 352-361, 2013.

[14] P. Hofmann, C. Homann, W. Leiling et al., Experimental and Calculational Results of the Experiments QUENCH-02 and QUENCH-03, Wissenschaftliche Berichte, FZKA 6295, Projekt Nukleare Sicherheitsforschung, Forschungszentrum, Institut für Materialforschung, Institut für Reaktorsicherheit, Karlsruhe, Germany, 2000.

[15] P. Kruse and K. M. Koch, "Simulation of the fuel rod bundle test QUENCH-03 using the integral code ASTEC V2," in Proceedings of the 8th International Topical Meeting on Nuclear Thermal-Hydraulics, Operation and Safety (NUTHOS8), N8P0058, Shanghai, China, October 2010.

[16] W. Hering, C. Homann, and J. S. Lamy, "Comparison report on the blind phase of the OECD International Standard Problem No.45 exercise (QUENCH-06)," Wissenschaftliche Berichte, FZKA-6677, 2002.

[17] C. M. Allison and R. J. Wagner, "RELAP5/SCDAPSIM/MOD3.2 $(\mathrm{am}+)$ Input Manual Supplemental," Innovative Systems Software, LLC, 2001, http://www.relap.com/.

[18] S. Sadek, S. Spalj, and D. Grgic, "RELAP5/SCDAPSIM analysis of the QUENCH-06 experiment," FER-ZVNE/SA/DA-IR01/03$0,2003$.

[19] J. H. Spencer, D. Novog, J. K. Hohorst, and C. M. Allison, "Assessment of new modeling in RELAP/SCDAPSIM using experimental results from the QUENCH program," in Proceedings of the International Congress on Advances in Nuclear Power Plants (ICAPP '11), Paper 11081, Nice, France, May 2011.

[20] L. Fernandez-Moguel and J. Birchley, "Analysis of QUENCH-10 and -16 air ingress experiments with SCDAPSim3.5," Annals of Nuclear Energy, vol. 53, pp. 202-212, 2013.

[21] J. Stuckert, M. Große, U. Stegmaier, and M. Steinbrück, "Results of severe fuel damage experiment QUENCH-15 with ZIRLOTM cladding tubes," KIT-SR 7576, Karlsruhe Institute of Technology, 2011.

[22] T. Kaliatka, E. Ušpuras, and A. Kaliatka, "Modelling of QUENCH 03 and QUENCH 06 experiments using RELAP/ SCDAPSIM code," in Proceedings of the 21st International Conference on Nuclear Engineering (ICONE '13), ASME, Chengdu, China, August 2013.

[23] E. Chojnacki and J. Baccou, "SUNSET V_2011_06_07 theory manual and user guide," Tech. Rep. DPAM-SEMIC-2011-225, 2011.

[24] H. Madokoro, K. Okamoto, and Y. Ishiwatari, "SCDAP model improvement with QUENCH-06 analysis," in Proceedings of the 22th International Conference on Nuclear Engineering (ICONE 22), pp. 1-8, ASME, Prague, Czech Republic, July 2014.

[25] J.-P. van Dorsselaere, C. Seropian, P. Chatelard et al., "The ASTEC integral code for severe accident simulation," Nuclear Technology, vol. 165, no. 3, pp. 293-307, 2009.

[26] W. Hering, C. Homann, J. S. Lamy et al., "Comparison and Interpretation Report on the OECD International Standard Problem No. 45 Exercise (QUENCH-06)," FZKA 6722, 2002. 


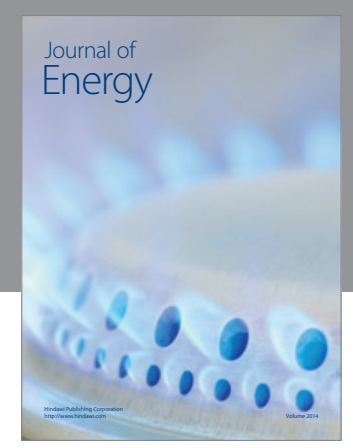

Journal of

Industrial Engineering
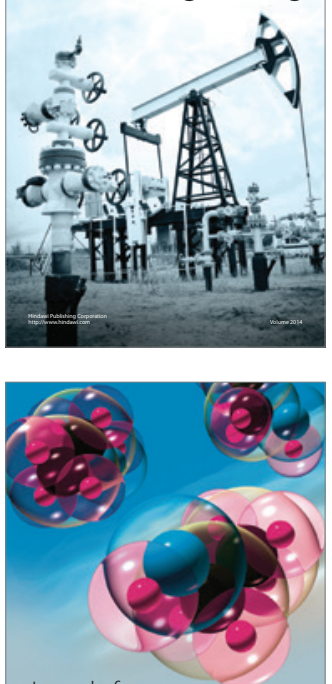

Fuels
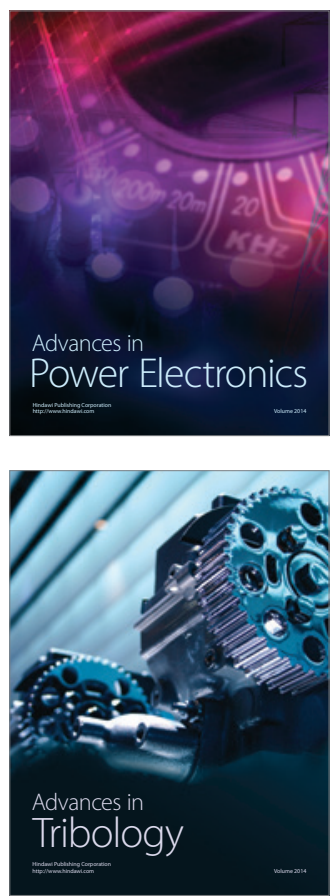

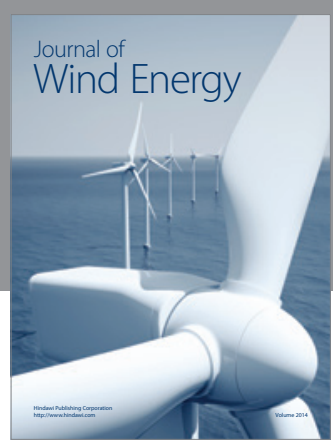

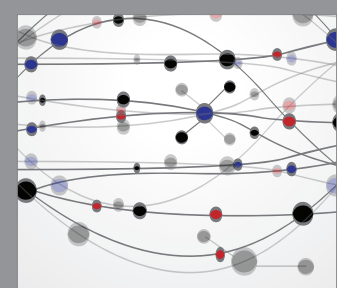

The Scientific World Journal

Submit your manuscripts at http://www.hindawi.com

Journal of

Structures
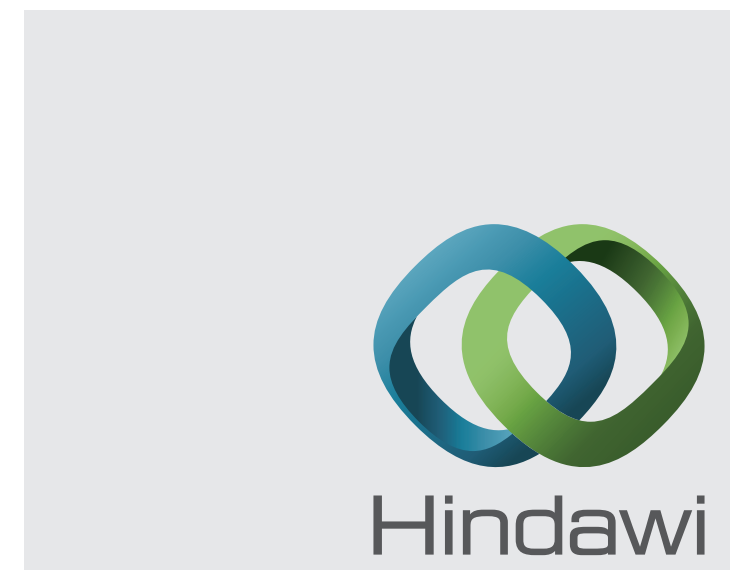

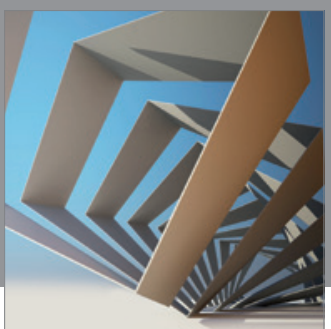

Rotating

Machinery
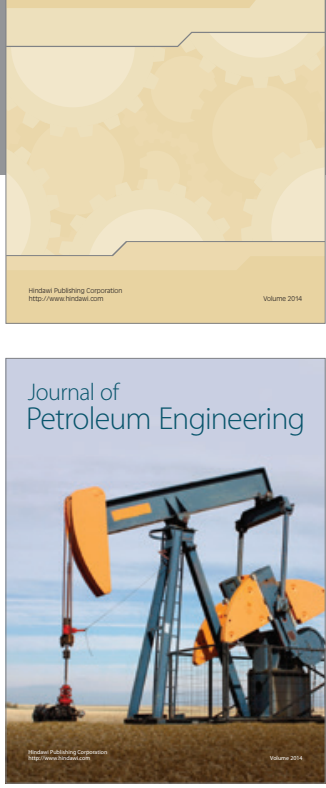

Journal of

Solar Energy
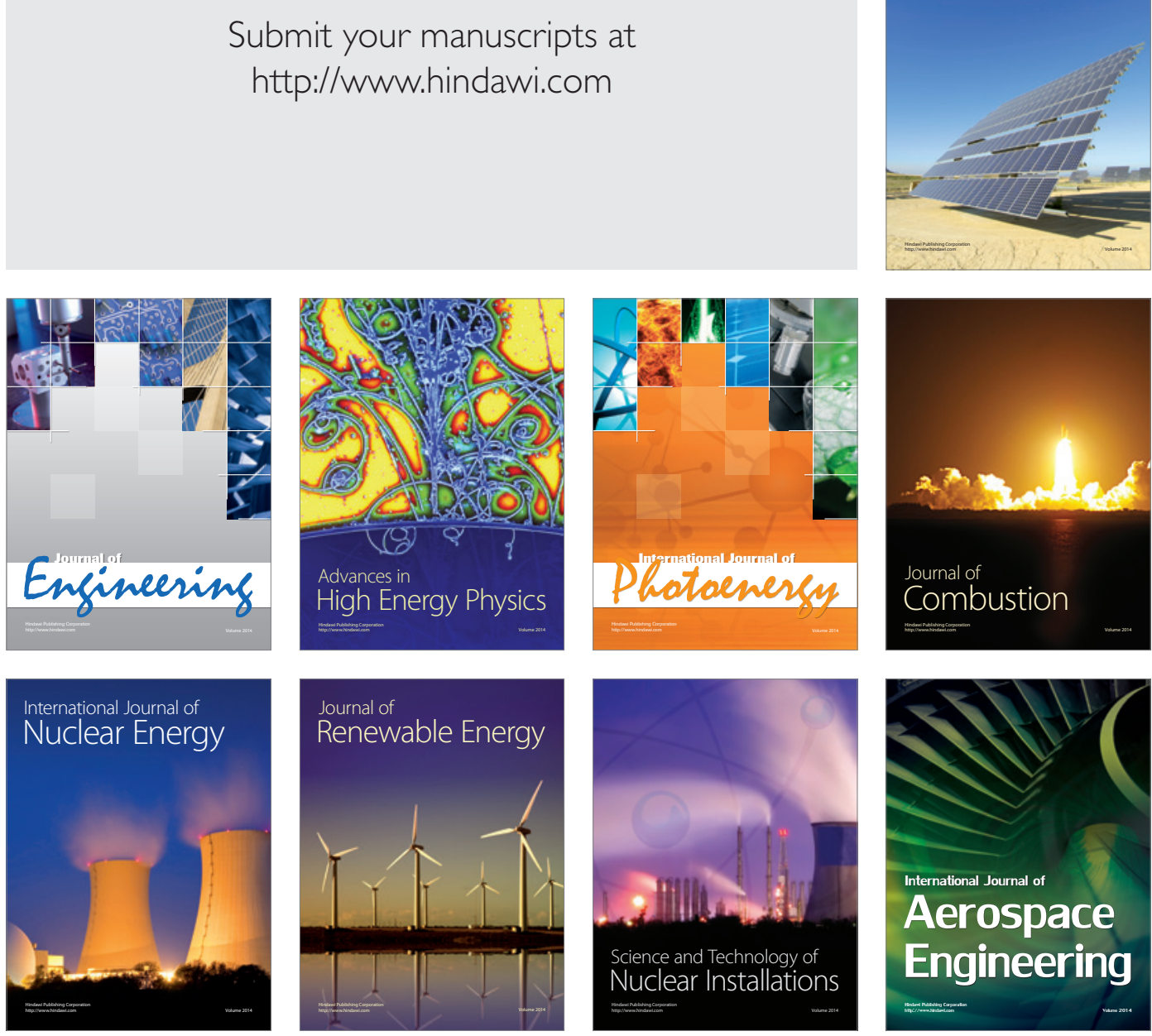